\title{
Effect of a Computer Mediated Systems Teaching Approach on Mathematics Anxiety of Engineering Students
}

\author{
Yusuf Iliyasu $^{1, *}$ \\ ${ }^{1}$ Department of Mathematics, Statistics \& Computer Science, College of Science \& \\ Technology, Kaduna Polytechnic, Kaduna, Nigeria \\ *Correspondence: Department of Mathematics, Statistics \& Computer Science, College of \\ Science \& Technology, Kaduna Polytechnic, Kaduna, Nigeria. Tel: 234-802-364-5895, \\ 234-703-098-4442. E-mail: iliyasuyg@yahoo.com, iliyasuyusufgobir@gmail.com
}

Received: May13, 2014

Accepted: July 21, 2014 Published: July 28, 2014

doi:10.5296/ije.v6i3.6043ＵRL: http://dx.doi.org/10.5296/ije.v6i3.6043

\begin{abstract}
The effect of a Computer Mediated Systems Teaching Approach (CMSTA) on engineering students' mathematics anxiety was investigated and reported in this paper. Specifically, the study determined (a) if the mean Mathematics Anxiety Level (MAL) of the students taught mathematics using the CMSTA will be significantly lower than that of those not taught with the same approach and (b) whether the MALs of the students taught mathematics using the CMSTA will significantly differ by gender? A sample of 470 students (with 267 in the experimental and 203 in control groups) and 445 students (with 256 in the experimental and 189 in control groups) took the pretest and posttest respectively. A four stage procedure was adopted for the experiment where treatment administration lasted for 12 weeks. Pretest and posttest administration of the Revised Mathematics Anxiety Rating Scale (RMARS) on the subjects showed that while significant difference was found between the mean MAL of the experimental and control groups, none was found between that of the male and female students taught mathematics using the CMSTA.
\end{abstract}

Keywords: computer mediated systems teaching approach, mathematics anxiety 


\section{Introduction}

The need for computer usage in education is no longer debatable. However, the assertion that most schools in many developing countries use 19th century technologies and methods to teach (Commonwealth Secretariat, 1991) still persists. This situation is perturbing because in this global information revolution era, schools are no longer expected to continue to offer a curriculum based on a view of information which dates back to the time when knowledge seem stable and bounded (Commonwealth Secretariat, 1991). It is observed that this is the current situation regarding the teaching/learning of mathematics at the various tiers of Nigeria's education system, which has been bedeviled by students' exhibition of high Mathematics Anxiety Levels (MALs), amongst other problems. It is believed that the opportunities afforded by new, improved and emerging technological developments in the field of Information and Communications Technology (ICT) have the potential of providing the much needed impetus for addressing this problem. The use of the Computer Mediated Systems Teaching Approach (CMSTA) to teach mathematics, whose effect on MAL of engineering students was investigated in this study, is hinged on the premise that computers are not only veritable means of enhancing students mathematics learning process, but can also be used to address challenges mathematics anxiety poses to mathematics learning.

From the time computers began to be used to enhance the teaching/learning process, which dates back to the 1950s (O'shea\& self, 1983), Leinonen (2005) summarily posits that the Programming, Drill and Practice phase, the Computer Based Training (CBT) with multimedia phase, the Internet Based Training (IBT) phase, the e-Learning phase and the Social Software plus Free and Open content phase are the main paradigm shifts that characterizes this five major phases portraying various efforts in the deployment of computers to enhance the teaching/learning process. These changing phases conform to observations from literatures on curriculum studies that a major area of concern in the deployment of technology in education is how best to utilize technological advancements to prepare students for a society that is increasingly being technologically driven. Using technology to address mathematics anxiety is believed to be an effort in this direction; particularly that literature review revealed that researches on the use of computers in Nigeria's education system were not focused on finding their effects on engineering students MALs. In addition therefore, this study is an effort to close the existing dearth of research work on the effect of computer usage on engineering students MALs.

\section{Conceptual Framework}

\subsection{Computer Mediated Systems Teaching Approach (CMSTA)}

Herein, CMSTA is defined with substantial recourse to the definition of Computer Mediated Communication (CMC) because teaching, in all its ramifications, is an activity which is basically communicative in nature. CMC has been defined as any communicative transaction which occurs through the use of two or more networked computers (McQuail, 2005). Traditionally, the term CMC was used in reference to communications that occur via 
computer - mediated formats such as instant messages, e-mails and chat rooms. Later on, the term was applied to other forms of text-based interactions such as text messaging (Thurlow et. al., 2004). Popular forms of CMC include e-mail, video, audio or text chat, bulletin boards, list-servs, Massively Multiplayer Online (MMOs) Games and Weblogs (blogs).

In line with the above, CMSTA is herein conceptualized to signify the ways in which telecommunication technologies could be merged with computers and computer networks to give teachers new tools to facilitate teaching. In other words, CMSTA describes the ways teachers could use computer systems and networks to transfer, store and retrieve information for the purpose of facilitating the teaching process. Implied in this conception is the notion that computers and computer network are taken as a single entity which is primarily a medium for supporting the teaching/learning process rather than being the teacher. In order to support the teaching/learning process, CMSTA entails the use electronic mail and real-time chat capabilities to deliver instructions and facilitate student-to-student as well as student-to-teacher interactions across a desk, classroom or the world.

\subsection{Mathematics Anxiety}

Mathematics anxiety is a phenomenon that is often considered when examining students' problems in mathematics. One of the earliest definitions of mathematics anxiety was that provided by Richardson \&Suinn (1972) as feelings of tension and anxiety that interfere with the manipulation of numbers and the solving of mathematical problems in a wide variety of ordinary life and academic situations. Subsequently, mathematics anxiety was variously defined by May (1977) as the feelings of uncertainty and helplessness in the face of danger; Cemen (1987) in Trujillo et. al., (1999) as a state of anxiety which occurs in response to situations involving mathematics that are perceived as threatening to self-esteem; Ashcraft \& Faust (1994) as the feeling of tension, helplessness, mental disorganization and dread one has when required to manipulate numbers and shapes and the solving of mathematical problems; Ashcraft (2002) as a feeling of tension, apprehension, or fear that interferes with mathematics performance.

Others defined mathematics anxiety in terms of a chain reaction. For example, Mitchell (1987) stated that mathematics anxiety experienced in the present has its roots in the past. Anxiety is perpetuated through negative self-talk manifesting in beliefs which cause anxiety. This leads to physical symptoms, an inability to think and avoidance which, in turn, leads to the inability to perform, causing anxiety and more negative self-talk, and the continuation of the mathematics anxiety cycle (Mitchell, 1987). This cycle leads to negative educational and societal mathematics attitudes which often become a self-fulfilling prophecy, and generally leads to mathematics avoidance (Williams, 1988).

Recognizing the complexity of mathematics anxiety is key to understanding the phenomenon. Mathematics anxiety is not a discrete condition but rather it is a construct with multiple causes and multiple effects interacting in a tangible manner that defies simple diagnosis and simplistic remedies (Martinez \& Martinez, 1996). Smith and Smith’s (1998) definition takes into consideration this intricacy by encompassing both the affective and cognitive domains of learning. In line with this, mathematics anxiety was defined as a feeling of intense frustration 
or helplessness about one's ability to do mathematics, and can be described as a learned emotional response to participating in a mathematics class, listening to a lecture, working through problems, and/or discussing mathematics to name but a few examples (Hembree, 1990; Le Moyne College, 1999).

In this work, mathematics anxiety is conceptualized in line with both Smith \& Smith's (1998) as well as Aschraft's (2002) definition to mean the exhibition of a feeling of intense frustration or helplessness about ones mathematics performance ability that creates tension, apprehension or fear in the individual which eventually interferes with his mathematics performance.

\section{Theoretical Framework}

Increasing recognition of the potentials of computer usage in the teaching/learning process has encouraged innovative approaches to the design of both classroom and distance teaching/learning. These approaches have contributed to a movement away from the duplication of traditional instructional methods, both in the classroom and at a distance (Turoff, 1995) towards more resource-based ones that no longer emphasize the teacher as the main source of knowledge (Smith and Kelly, 1987; Beaudoin, 1990; Gunawardena, 1992). Garrison (1993) and Crotty (1994) held that this perspective within technology use in education aligns itself with the principles of constructivism. In this study, it is thus held that the pedagogical basis for the use of computers to enhance the teaching/learning process lies within the principles of constructivism. Therefore, the theoretical framework guiding this study is positioned within the principles of constructivism.

As a theory based on observation and scientific study about how people learn, constructivism holds that people construct their own understanding and knowledge of the world through experiencing things and reflecting on those experiences, i.e. we are active creators of our own knowledge. Constructivist approaches were followed in the deployment of the CMSTA when tools such as discussion forums, wikis and blogs were used in such a way as to enable learners to actively engage in knowledge construction.

\section{Problem Statement}

It was observed that (i) new technologies are failing to penetrate the Nigerian education system (Nnoli and Sulaiman, 2001) despite Nigeria's National Policy on Education's (FGN, 2004) categorical emphasizes that modern educational techniques shall be increasingly used and improved upon at all levels of the educations system, (ii) the teaching of mathematics to engineering students in most tertiary institutions in Nigeria is largely performed using traditional approaches ( i.e. talk and chalk) despite the fact that the use of multimedia courseware in engineering has rapidly gained popularity (Reagan and Shepard, 1996), (iii) mathematics teaching in Nigeria is lagging behind the teaching of other subjects like physics, chemistry and biology in term of experimentation, despite the fact that it has been established 


\section{Macrothink}

International Journal of Education ISSN 1948-5476 2014, Vol. 6, No. 3

that experiments help students in their learning (Bourne et al, 1996). These shortcomings might have been responsible for some observed high MALs exhibited by many engineering students in tertiary institutions in Nigeria. High MAL can constitute stumbling blocks to the students' full understanding of the applications of mathematics in the engineering profession. Based on the belief that computer usage in the teaching/learning process is capable of not only increasing students' mathematics achievement, but can also help in lowering their MALs; this study was therefore undertaken with the hope that the use of the CMSTA will address this problem.

\section{Objectives}

The main purpose of carrying out this research work was to take advantage of emerging new technologies in the field of Information and Communications Technology (ICT) to study the effects of a CMSTA on mathematics anxiety of engineering students. Specifically, the study sought to determine:

1. If the mean MAL of the students taught mathematics using the CMSTA will be significantly lower than that of those not taught with the same approach?

2. Whether the MALs of the students taught mathematics using the CMSTA will significantly differ by gender?

\section{Research Questions}

1. Will the mean MAL of the students taught mathematics using the CMSTA be lower than that of those not taught with the same approach and to what extent?

2. Which gender will exhibit lower MAL amongst the students taught mathematics using the CMSTA and to what extent?

\section{Research Hypotheses}

Ho $_{1}$ : There is no significant difference between the mean MAL of the students taught mathematics using the CMSTA and that of those not taught with the same approach.

Ho$_{2}$ : Gender difference in the MALs of the students taught mathematics using the CMSTA is not significant.

\section{Methodology}

\subsection{Research Design}

This quasi - experimental research adopted the pretest-posttest Non Equivalent Groups Design (NEGD) approach. 


\subsection{Sample and Sampling Procedure}

Both control and experimental groups were drawn from Kaduna Polytechnic. Situated in the northwest of Nigeria, this institution is one of the largest of its kind in terms of student and staff population, courses offered, infrastructure and facilities. It is therefore believed that generalization of results obtained from sample drawn from the institution suffices. Subjects targeted were students of National Diploma I \& II (i.e. NDI \& NDII) as well as Higher National Diploma I \& II (i.e. HNDI \& HNDII) levels. The treatment was administered during the second semester of the 2010/2011 academic session. Only NDI and HNDI students take second semester mathematics courses. Consequently, the study sample was drawn from NDI and HNDI. The experimental and control groups were drawn from departments in the Schools of Industrial Engineering and Natural Resources Engineering respectively. In each school, one HNDI and one NDI class were randomly chosen. A sample of 470 students (with 267 in the experimental and 203 in control groups) and 445 students (with 256 in the experimental and 189 in control groups) took the pretest and posttest respectively. Table 1 shows the detail breakdown of sample of the study.

The difference between the number of students who took the pretest and posttest was attributed to the fact that there was attrition in the period between the pretest and posttest. A combination of the convenience, purposive and random sampling procedures was adopted to select the samples used. The convenience sampling procedure was adopted when Kaduna Polytechnic was chosen as the institution where the study was to be conducted. For, the researcher is a staff of the institution and therefore using students of the institution will be most convenient to him. Since only students that offer mathematics courses in the semester in which the experiment was carried out could be used, purposive sampling procedure was therefore employed in the determination of the level whose students were used. The random sampling procedure was used to assign the schools into both the control and experimental groups. It was also employed to choose the levels used in each group.

Table 1. Distribution of sample of the study

\begin{tabular}{|c|c|c|c|c|c|}
\hline \multirow{2}{*}{ Group } & \multirow{2}{*}{ Department } & \multirow{2}{*}{ Level } & \multirow{2}{*}{ Sex } & \multicolumn{2}{|c|}{ Sample } \\
\hline & & & & Pretest & Posttest \\
\hline \multirow{7}{*}{ Experimental } & \multirow{3}{*}{ Chemical Engineering } & \multirow{3}{*}{ HND I } & $\mathrm{M}$ & 113 & 111 \\
\hline & & & $\mathrm{F}$ & 31 & 28 \\
\hline & & & Total & 144 & 139 \\
\hline & \multirow{3}{*}{ Computer Engineering } & \multirow{3}{*}{ ND I } & M & 99 & 97 \\
\hline & & & $\mathrm{F}$ & 24 & 20 \\
\hline & & & Total & 123 & 117 \\
\hline & \multirow{2}{*}{\multicolumn{2}{|c|}{ Sub Total }} & & 267 & 256 \\
\hline \multirow{8}{*}{ Control } & & & M & 105 & 95 \\
\hline & \multirow[t]{2}{*}{ Civil Engineering } & \multirow[t]{2}{*}{ HND I } & $\mathrm{F}$ & 10 & 8 \\
\hline & & & Total & 115 & 103 \\
\hline & \multirow{3}{*}{$\begin{array}{l}\text { Mineral Resources } \\
\text { Engineering }\end{array}$} & \multirow{3}{*}{ ND I } & $\mathrm{M}$ & 71 & 71 \\
\hline & & & $\mathrm{F}$ & 17 & 15 \\
\hline & & & Total & 88 & 86 \\
\hline & \multicolumn{3}{|c|}{ Sub Total } & 203 & 189 \\
\hline & \multicolumn{2}{|c|}{ Grand Total } & & 470 & 445 \\
\hline
\end{tabular}




\subsection{Instrumentation}

The Revised Mathematics Anxiety Rating Scale (RMARS), a 24-item instrument designed by Suinn and Winston (2003) to measure the degree of mathematics anxiety of respondents, was adapted and used. RMARS uses a five point Likert scale format with the following categories: 1 for not at all, 2 for a little, 3 for a fair amount, 4 for much and 5 for very much. For each RMARS, the total score ranges from 24 to 120, with higher scores correlating with higher MALs. The MAL of subjects with total a RMARS score from $24-47$ was adjudged to be very low; 48 - 71, low; 72 - 95, high and 96 - 120, very high. From this categorization, it follows that the minimum score for a student to be adjudged to have exhibited high mathematics anxiety is 72 .

Suinn and Winston (2003) reported that the RMARS has a Cronbach alpha of 0.96 and a test-retest reliability coefficient of $0.90(p<.001)$, indicating that it has high internal consistency and very reliable. However, the need to determine new reliability estimate for the RMAR used in relation to this study became pertinent since adaptation of the instrument demands that some items have to be modified while others were discarded and replaced. A pilot test was thus carried out during the first semester of the 2010/2011 academic session. The data obtained from the pilot study was analyzed to determine the difficulty and discrimination indices of each item as well as the reliability coefficient of the instrument. The reliability coefficient of the RMARS used was determined by subjecting the scores obtained from the pilot study to the Kuder-Richardson Formula 21 where a reliability coefficient of 0.94 was obtained. This suggests that the RMARS used was quite a reliable measuring instrument for the study.

\subsection{Treatment and Treatment Procedure}

The control group was taught mathematics using the conventional approach while the experimental group was taught with the CMSTA. The CMSTA, which was adapted from Nordinet. al.'s (2005) eLearning instructional approach design model, has three main features, viz: Mathematics Teaching Approaches (MTA), Lesson Sequencing Approaches (LSA), and Modularization of MTA and LSA. MTA has six features, viz: the expository, modeling, coaching, articulation, reflection and exploration approaches. LSA has three components, viz: scaffolding, increasing complexity and increasing diversity. Each module has four main submodules built into each mathematics course materials taught, viz: Teacher, Revision, Exercise and Reinforcement submodules. After assignment of subject to experimental and control groups, administration of the treatment lasted for 12 weeks.

\subsection{Data Collection and Analysis Procedures}

The RMARS was administered at the beginning and end of the second semester of the 2010/2011 academic session as pretest and posttest respectively by the researcher. The Mean, Standard Deviation, Standard Error of the Mean and t-test statistics were used for data analyses. The hypotheses were tested at the $95 \%$ confidence level. 


\section{Macrothink}

\section{Results}

\subsection{Descriptive Statistics}

To answer the research questions, the Mean, Standard Deviation and Standard Error of the Mean (see Table 2) were computed. Results obtained showed that:

1) the pretest and posttest mean RMARS scores of males (i.e. 46.14 and 34.01) in the experimental group were lower than that of their counterparts in the control group (i.e. 46.91and 45.53 ) by 0.77 and 11.52 respectively.

2) while the pretest mean RMARS scores of females (i.e. 45.77) in the experimental group was higher than that of their counterparts in the control group (i.e. 45.44) by 0.33 , the posttest mean RMARS scores of females (i.e. 33.73) in the experimental group was lower than that of their counterparts in the control group (i.e. 45.44) by 11.71 .

3) the pretest mean RMARS scores of the experimental group (i.e. 46.10) was lower than that of the control group (i.e. 46.70) by 0.6 and posttest mean RMARS scores of the experimental group (i.e. 34.00) was also lower than that of the control group (i.e. 45.50) by 11.50 .

4) the pretest and posttest mean RMARS scores of females in the experimental group were lower than that of their male counterparts by 0.37 and 0.28 respectively.

From (1) - (3) above, it therefore follows that the experimental group exhibited lower mathematics anxiety than the control group. Also, (4) above implies that the female students taught mathematics using the CMSTA exhibited lower MALs than their male counterparts.

Table 2. Descriptive Statistics of RMARS scores by Group, Gender and Test-Type

\begin{tabular}{lllllllll}
\hline Group & Gender & Test & $\mathbf{N}$ & Min & Max & Mean & SD & $\mathbf{S}_{\mathbf{e}}$ \\
\hline \multirow{2}{*}{ Male } & Pretest & 208 & 24 & 100 & 46.14 & 18.57 & 1.29 \\
& & Posttest & 212 & 24 & 79 & 34.01 & 14.12 & 0.97 \\
Experimental & \multirow{2}{*}{ Female } & Pretest & 48 & 24 & 93 & 45.77 & 18.50 & 2.67 \\
& & Posttest & 55 & 24 & 75 & 33.73 & 13.92 & 1.88 \\
& \multirow{2}{*}{ Both } & Pretest & 256 & 24 & 100 & 46.10 & 18.52 & 1.16 \\
& \multirow{3}{*}{ Male } & Posttest & 267 & 24 & 79 & 34.00 & 14.05 & 0.86 \\
& & Pretest & 166 & 24 & 101 & 46.91 & 18.77 & 1.46 \\
& \multirow{3}{*}{ Fontrol } & Posttest & 176 & 24 & 101 & 45.53 & 19.02 & 1.43 \\
& \multirow{2}{*}{ Female } & Pretest & 25 & 24 & 81 & 45.44 & 15.61 & 3.12 \\
& & Posttest & 25 & 24 & 81 & 45.44 & 15.55 & 3.11 \\
& \multirow{2}{*}{ Both } & Pretest & 191 & 24 & 101 & 46.70 & 18.36 & 1.33 \\
& & Posttest & 201 & 24 & 101 & 45.50 & 18.59 & 1.31 \\
\hline
\end{tabular}




\subsection{Inferential Statistics}

To test the research hypotheses at the 95\% confidence level, the t-test statistics was employed. Results obtained showed that:

(1) While the difference between the:

a) pretest and posttest mean RMARS scores of the control group was not significant, it was significant for the subjects in the experimental group (see Table 3).

Table 3. Paired Sample t-test Analysis of Significance between the Pretest and Posttest RMARS scores by Groups

\begin{tabular}{lllllllll}
\hline Variable & Group & Test & N & Mean & SD & df & t & p \\
\hline \multirow{3}{*}{ RMARS } & \multirow{2}{*}{ Control } & Pretest & 189 & 46.96 & 18.31 & & & \\
Scores & & Posttest & 189 & 46.86 & 18.37 & 188 & 1.40 & 0.20 \\
& \multirow{2}{*}{ Experimental } & Pretest & 256 & 46.07 & 18.52 & & & \\
& & Posttest & 256 & 34.38 & 14.2 & 255 & 28.78 & $0.00^{*}$ \\
& & & & & & & & \\
\hline
\end{tabular}

${ }^{*} \mathrm{p}<.05$

b) experimental and control groups' the pretest mean RMARS scores was not significant, it was significant in the case of posttest scores (see Table 4).

Table 4. Independent Sample t-test Analysis between Experimental and Control Group RMARS Scores by Test-Types

\begin{tabular}{lllllllll}
\hline Variable & Test & Group & N & Mean & SD & df & t & p \\
\hline \multirow{3}{*}{ RMARS } & \multirow{2}{*}{ Pretest } & Experimental & 256 & 46.07 & 18.52 & & & \\
Scores & & Control & 191 & 46.72 & 18.36 & 445 & -0.37 & 0.70 \\
& \multirow{2}{*}{ Posttest } & Experimental & 267 & 33.95 & 14.05 & & & \\
& & Control & 201 & 45.52 & 18.59 & 466 & -7.67 & $0.00^{*}$ \\
\hline
\end{tabular}

$* \mathrm{p}<.05$

c) pretest and posttest mean RMARS scores of both the males and females in the control group were not significant, these differences were significant for both males and females in the experimental group (see Table 5). 
Table 5. Paired Sample t-test Analysis of Significance between the Pretest and Posttest RMARS Scores by Groups and Gender

\begin{tabular}{|c|c|c|c|c|c|c|c|c|c|}
\hline Variable & Group & Gender & Test & $\mathbf{N}$ & Mean & SD & df & $\mathbf{t}$ & $\mathbf{p}$ \\
\hline \multirow{8}{*}{$\begin{array}{l}\text { RMARS } \\
\text { Scores }\end{array}$} & \multirow{4}{*}{ Control } & \multirow{2}{*}{ Male } & Pretest & 166 & 46.91 & 19 & \multirow{2}{*}{165} & \multirow{2}{*}{1.40} & \multirow{2}{*}{0.16} \\
\hline & & & Posttest & 166 & 46.83 & 19 & & & \\
\hline & & \multirow{2}{*}{ Female } & Pretest & 23 & 47.30 & 15 & \multirow{2}{*}{22} & \multirow{2}{*}{0.60} & \multirow{2}{*}{0.56} \\
\hline & & & Posttest & 23 & 47.04 & 15 & & & \\
\hline & \multirow{4}{*}{ Experimental } & \multirow{2}{*}{ Male } & Pretest & 208 & 46.14 & 19 & \multirow{2}{*}{207} & \multirow{2}{*}{26.16} & \multirow{2}{*}{$0.00^{*}$} \\
\hline & & & Posttest & 208 & 34.20 & 14 & & & \\
\hline & & \multirow{2}{*}{ Female } & Pretest & 48 & 45.77 & 19 & \multirow{2}{*}{47} & \multirow{2}{*}{12.09} & \multirow{2}{*}{$0.00^{*}$} \\
\hline & & & Posttest & 48 & 35.15 & 14 & & & \\
\hline
\end{tabular}

$* p<.05$

(2) Experimental group's male and female pretest as well as posttest mean RMARS scores were not significant (see Table 6).

Table 6. Independent Sample t-test Analysis of Significance between the Male and Female RMARS Scores by Groups and Test-Types

\begin{tabular}{|c|c|c|c|c|c|c|c|c|c|}
\hline Variable & Group & Test & Gender & $\mathbf{N}$ & Mean & SD & df & $\mathbf{t}$ & $\mathbf{p}$ \\
\hline \multirow{4}{*}{$\begin{array}{l}\text { RMARS } \\
\text { Scores }\end{array}$} & \multirow{4}{*}{ Experimental } & \multirow{2}{*}{ Pretest } & Male & 208 & 46.14 & 19 & \multirow{2}{*}{254} & \multirow{2}{*}{0.12} & \multirow{2}{*}{0.9} \\
\hline & & & Female & 48 & 45.77 & 19 & & & \\
\hline & & \multirow{2}{*}{ Posttest } & Male & 212 & 34.01 & 14 & \multirow{2}{*}{265} & \multirow{2}{*}{0.13} & \multirow{2}{*}{0.9} \\
\hline & & & Female & 55 & 33.73 & 14 & & & \\
\hline
\end{tabular}

From (1a) and (1b) above, Ho $\mathbf{H o}_{1}$ is therefore rejected and the alternative upheld. Also (1c) and (2) implies that $\mathbf{H o}_{2}$ has to be upheld and the alternative rejected.

\section{Findings and Discussion}

\subsection{Findings}

1. The MALs of the students taught mathematics using the CMSTA was significantly lower than that of those not taught with the same approach.

2. Though the mean RMARS scores of students taught mathematics using the CMSTA differ in favour of the females, gender difference in MALs of students taught using the CMSTA was not significant.

\subsection{Discussion}

The rejection of $\mathbf{H o}_{1}$ may be attributed to the effect of treatment on the experimental group. This line of reasoning is supported by the fact that while no significant difference was found between the pretest and posttest mean RMARS scores of subjects in the control groups, as for 
the subjects in the experimental group this difference was significant. Also, the result suggests no significant difference between the experimental and control groups pretest mean RMARS scores while for the posttest scores, this difference was significant.

This result is similar to that obtained by Taylor (2008), who set forth to examine the effects a web-based, computer-assisted curriculum in remedial mathematics classes on mathematics anxiety in addition to the main purpose of her study which was to look at differences in student achievement in a web-based, computer-assisted curriculum in remedial mathematics classes as compared to classes that use traditional lecture method of instruction. She reported statistically significant differences from pretest to posttest for the experimental group, no statistically significant differences from pretest to posttest for the control group, and statistically significant differences from pretest to posttest for both (experimental and control) groups. She further reported that the anxiety levels of the experimental and control groups both decreased, but the anxiety level of the experimental group decreased more than that of the control group. In view of these results, she posits that in addition to the mathematics anxiety of the experimental group being less than that of the control group, it decreased at a greater rate in the experimental group than the control group.

The retention of the $\mathbf{H o}_{2}$ may be attributed to the effect of treatment on the experimental group, as being homogenous. This line of reasoning is supported by the fact that both males and females in the experimental group were exposed to the same treatment at the same time and under the same condition throughout the treatment period. Therefore, it is only natural that since the treatment has impacted on the experimental group, as can be seen from the rejection of $\mathbf{H o}_{1}$, both genders would have contributed approximately equally towards the result. In this regard, the results suggest that while no significant difference was found between the pretest and posttest mean RMARS scores for both male and female subjects in the control group; in the case of the male and female subjects in the experimental group the difference was significant. Furthermore, the result indicates no significant difference between the male and female pretest as well as posttest mean RMARS scores for the experimental group.

This finding is similar to that obtained by Gierl and Bisanz (1995) who found no significant gender difference in the mathematics anxiety in the early grades. However, this result is different from that obtained by Bernstein, Reilly, and Cote-Bonanno (1992) as well as Campbell and Evans (1997) who reported that females exhibit more mathematics anxiety in secondary schools and colleges.The belief that this finding is attributed to the treatment is further supported by research findings which suggested that teachers can prevent and reduce mathematics anxiety bydesigning better teaching practices (Cornell, 1999; Steele and Arth, 1998), creating a comfortable atmosphere (Jackson and Leffingwell, 1999; Steele and Arth, 1998), providing encouragement (Godbey, 1997; Jackson and Leffingwell, 1999) etc. This study was an effort in that direction. 


\section{Conclusion and Recommendations}

Research on the effects of computer-based instruction encountered during literature search revealed that the positive effects of the use of computers for teaching to supplement regular instruction includes its ability to make students (a) learned more in less time, (b) had slightly higher grades on posttests, and (c) had improved attitudes toward learning (Kinney et.al., 2004; Kulik\&Kulik, 1991). In addition it was found that students benefited from computer-mediated learning when all students meet at the same time with the same instructor, which gave them a sense of community, and the students were more likely to meet the course objectives on schedule (Kinney \& Robertson, 2003). Mediated learning offers students an alternative to the direct-instruction approach used in traditional lecture classes (Lundellet.at., 2001).

In view of the results obtained in this study and other similar ones from related studies, it was generally concluded that the treatment was able to lower the students' MALs. Based on the findings of this study and other related ones, the following recommendations are put forward:

1. The CMSTA should be adopted/adapted widely by mathematics teachers/lecturers in Nigerian tertiary institutions to teach engineering students.

2. Use of ICT in teaching should be integrated into the mathematics education curricular of all levels of education in Nigeria.

3. Government should enact policies that will encourage mathematics educators, ICT experts and community members to collaborate to create strategies to help achieve the goals of integrating ICT into the mathematics education curriculum.

4. Mathematics teachers/lecturers in Nigerian tertiary institutions should be supported by their institutions' authorities to continuously engage in professional development in the area of computer usage and applications in teaching.

5. An awareness program should be developed for reluctant students to explain the benefits of using computers, software and the internet in the teaching/learning process.

\section{Implications of the Findings}

All stake holders in the Nigerian education sector should put all hands on deck to begin to ensure that the full benefits of ICT integration into the teaching/learning process are fully harnessed. Based on the positive effects of technology integration into mathematics teaching on students' MAL, mathematics lecturers in tertiary institutions in Nigeria should be encouraged to develop teaching strategies which incorporates ICT usage that will help them address the challenges mathematics anxiety and other psychological constructs pose to mathematics learning. 


\section{Contributions of the Study to Knowledge}

It is believed that this study has:

1. added to the body of knowledge on the positive effect of deploying computers to enhance teaching and learning of mathematics in Nigeria thereby reducing the existing dearth of research work in this area.

2. provided mathematics teachers/lecturers teaching mathematics to engineering students in tertiary institutions in Nigeria with a framework which will assist them develop their customised computer application packages for the purpose of helping to reduce their students MAL.

3. contributed to literature which education policy makers in Nigeria may use to come up with new policies on computer usage in the teaching/learning process.

\section{Limitations of the Study}

There may be many other possible limitations of this study; one considered worthy of noting is that the length of the study was limited to one semester. A lengthier period of study may have produced a different result.

\section{Areas for Further Research}

A similar research on the effects of the CMSTA on MALs of other science and technology as well as social science and business studies students in Nigeria's tertiary institution should be undertaken.

\section{References}

Ashcraft, M. A. (2002). Math anxiety: Personal, educational, and cognitive consequences. Current Directions in Psychological Science, 11(5), 181-185.http://dx.doi.org/10.1111/1467-8721.00196

Ashcraft, M., \& Faust, M. (1994). Mathematics anxiety and mental arithmetic performance: An exploratory investigation. Cognition and emotion, 8(2), 97-125. http://dx.doi.org/10.1080/02699939408408931

Beaudoin, M. (1990). The instructor's changing role in distance education. The American Journal of Distance Education, 4(2), 21-29. http://dx.doi.org/10.1080/08923649009526701

Bernstein, J., Reilly, L., \& Cote-Bonanno, J. (1992). Barriers to women entering the workforce: Math anxiety. (Report No. CE 064 012). Montclair, NJ: Montclair State College, Life Skills Center. (Eric Document Reproduction Service No. ED 359 381) 
Bourne J.R., Brodersen, A.J., Campbell, J. O., Dawant, M. M., \& Shiavi, R. G. (1996).A Model for On-Line Learning Networks in Engineering Education. Journal of Engineering Education, 85(3), http://dx.doi.org/10.1002/j.2168-9830.1996.tb00241.x.

Campbell, K., \& Evans, C. (1997). Gender issues in the classroom: A comparison of mathematics anxiety. Education, 117(3), 332-339.

Common Wealth Secretariate (1991). Micro Computers In Schools: Policy And Implementation Guidelines. London: Common Wealth Secretariat Education Programme Human Resource Development Group.

Cornell, C. (1999). I hate math! I couldn’t learn it, and I can’t teach it! Childhood Education, 75(4), 225-231.

Crotty, T. (1994). Integrating distance learning activities to enhance teacher education toward the constructivist paradigm of teaching and learning. Proceedings of the Distance Learning Research Conference, Texas. In E. Pigliapoco, G. Torrisi, M. Messina \& A. Bogliolo. (2012). LoL Classroom: A Virtual University Classroom Based on Enhanced Chats. European Journal of Open, Distance and Learning (EURODL). Retrieved April 5, 2011 from http://www.eurodl.org/index.php?article=337

Ebel, R. L. (1975). Evaluation in Education. Cape Town: Maskew Miller Publishers.

FGN (Federal Republic of Nigeria). (2004). National Policy on Education (Revised). Lagos: NERC Press.

Garrison, R. (1993). Quality and access in distance education: Theoretical considerations. In D. Keegan (ed.): Theoretical Principles of Distance Education, New York: Routledge.

Gierl, M. J., \& Bisanz, J. (1995). Anxieties and attitudes related to mathematics in grade 3 and 6. Journal of experimental education, 63(2), 139-158. http://dx.doi.org/10.1080/00220973.1995.9943818.

Godby, C. (1997). Mathematics anxiety and the underprepared student. (Report No. JC 990 063). TN: Middle Tennessee State University. (ERIC Document Reproduction Service No. ED 426734). Retrieved January 12, 2007 from www.eric.ed.gov/ERICWebPortal/detail?accno=EJ1426734

Gunawardena, C. N. (1992): Changing faculty roles for audiographics and online teaching. The American Journal of Distance Education, 6(3), 58-71. http://dx.doi.org/10.1080/08923649209526800.

Hembree, R. (1990). The nature, effects, and relief of mathematics anxiety. Journal for Research in Mathematics Education, 21(1), 33-46. http://dx.doi.org/10.2307/749455

Jackson, C., \& Leffingwell, R. (1999). The role of instructors in creating math anxiety in students from kindergarten through college. Mathematics Teacher, 92(7), 583-587. (ERIC Document Reproduction Service No. ED 431 628) 
Kinney, D. P, Stottlemyer, J., Hatfield, J., \& Robertson, D. F. (2004). A comparison of the characteristics of computer-mediated and lecture students in developmental mathematics. Research and Teaching in Developmental Education, 21(1), 14-28.

Kinney, D. P., \& Robertson, D. F. (2003). Technology makes possible new models for delivering developmental mathematics instruction. Mathematics and Computer Education, 37, 315-328.

Kulik, C. L., \& Kulik, J. (1991). Effectiveness of Computer-Based Instruction: An Updated analysis. Computers in Human Behavior, 7(1-2), 75-94. http://dx.doi.org/10.1016/0747-5632(91)90030-5

Le Moyne College. (1999). Study skill guides: Math anxiety. Retrieved April 21, 2007 from http://www.lemoyne.edu/academic_support_center/mathanx.htm

Leinonen, T. (2005). (Critical) history of ICT in education - and where we are heading? Retrieved March 15, 2009 from http://flosse.blogging.fi/2005/06/23/critical-history-of-ict-in-education-and-where-we-ar e-heading/

Lundell, D. B., Higbee, J. L., Chung, C., Ghere, D., \& Kinney, D. R (2001). Setting the pace: Theoretical perspectives for developmental education. In M. R. Hay \& N. L. Ludman (Eds.), 2001 Selected conference papers (pp. 45-49). Dowagiac, MI: National Association for Developmental Education.

Martinez, J., \& Martinex, N. (1996). Math without fear. Needham Heights, MA: Allyn and Bacon.

May, R. (1977). The meaning of anxiety. New York: Norton.

McQuail, D. (2005). Mcquail's Mass Communication Theory. (5th ed). London: SAGE Publications.

Mitchell, C. E. (1987). Math anxiety: what it is and what to do about it. Tempe: Action.

Nnoli, O., \& Sulaiman, I. (2001). Reassessing the Future of Education in Nigeria. Nigeria: Education Tax Fund.

Nordin, N. M., Zaman, H. B., \& Din, R. (2005). Integrating Pedagogy and Instructional Design in the eLearning Approach for the Teaching of Mathematics. Proceedings of the Second International Conference on eLearning for Knowledge-Based Society, August 4-7, 2005, Bangkok, Thailand.

O’Shea, T., \& Self, J. (1983). Learning and Teaching with Computers. Great Britain: Harvest Press.

Reagan, M., \& Sheppard, S. (1996). Interactive Multi-media Courseware and the Hands-on Learning Experience: An Assessment Study. Journal of Engineering Education, 85(2), 89-172. http://dx.doi.org/ 10.1002/j.2168-9830.1996.tb00221.x 
Richardson, F. C., \& Suinn, R. M. (1972, November). The mathematics anxiety rating scale: Psychometric data. Journal of Counseling Psychology, 19(6), 551-554.

Smith, B. S., \& Smith, W. H. (1998).Coping with math anxiety. Retrieved June 20, 2008 from http://www.mathacademy.com/platonic_realms/minitext/anxiety.html

Smith, P., \& Kelly, M. (1987). Distance Education and the Mainstream. London: Croom Helm.

Steele, E., \& Arth, A. (1998). Lowering anxiety in the math curriculum. Education Digest, 63(7), 18-24.

Suinn R. M., \& Winston E. H. (2003, February): The Mathematics Anxiety Rating Scale, a brief version: psychometric data. Psychological Reports, 92(1), 167-73.

Taylor, J. M. (2008, Fall). The effects of a computerized-algebra program on mathematics achievement of college and university freshmen enrolled in a developmental mathematics course. Journal of College Reading and Learning, 39(1).

Thurlow, C., Lengel, L., \& Tomic, A. (2005). Computer mediated communication: Social interaction and the internet. London: Sage.

Trujillo, K. M., Hadfield., \& Oakley, D. (1999). Tracing the roots of mathematics anxiety through in-depth interviews with preservice elementary teachers. College Student Journal, 33(2), 11.

Turoff, M. (1995). Designing a virtual classroom. Paper presented at the International Conference on Computer Assisted Instruction. Retrieved June 20, 2008 from http://www.njit.edu/Department/ccc/vc/Papers/design.html

Williams, W. V. (1988). Answers to questions about maths anxiety. School science and mathematics, 88(2), 95-104.

\section{Copyright Disclaimer}

Copyright reserved by the author(s).

This article is an open-access article distributed under the terms and conditions of the CreativeCommons Attribution license (http://creativecommons.org/licenses/by/3.0/). 